\title{
INTERDISCIPLINARIDADE: UMA RELAÇÃO POSSIVEL NA UNIVERSIDADE?
}

\author{
$*$ \\ Francisco Nilton Gomes de Oliveira \\ Universidade Federal de Santa Maria - UFSM - Brasil

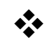

\section{Resumo}

O presente estudo é fruto da pesquisa desenvolvida pelo Grupo de Estudos sobre Universidade Pesquisa e Inovação da UFRGS, sob a supervisão da Professora Maria Estela Dal Pai Franco. O desafio da Interdisciplinaridade remete a questões constantes de reconstrução na formação humana, levando-se em consideração a história da existência do homem e suas transformações sociais, culturais e éticas. A Universidade exerce um papel culminante no que concerne a formação do sujeito, a qual, tendenciosamente, fragmenta o conhecimento, impondo uma visão tecnicista e positivista nos muros institucionais. Romper com essa tendência fragmentadora e desarticulada é uma forma de contribuir para novos cenários de saberes. A questão conceitual sobre a interdisciplinaridade se amplia, pois ela vai além dos muros da escola, inserindo-se nos processos de trabalho, no cotidiano das pessoas, aproximando-se de uma necessidade imediata humana devido às inúmeras demandas que são impingidas ao sujeito na sociedade contemporânea. A ação interdisciplinar é uma prática que permite aproximar o individuo nos diversos campos de saberes, gerando um benefício próprio ao ser humano, contribuindo, assim, para que as diferentes disciplinas alcancem a compreensão das diversidades e pluralidades humanas. $\mathrm{O}$ objetivo desta pesquisa consiste em analisar as práticas estabelecidas nos cursos de graduação dentro de uma concepção interdisciplinar. Em relação aos eixos metodológicos, o estudo é de natureza qualitativa e quantitativa. Foram entrevistados 30 (trinta) docentes da graduação na IES em diferentes cursos do Centro de Ciências da Saúde, através de uma escolha aleatória. A análise das falas foi efetivada por meio da análise de conteúdo, segundo princípios propostos por Bardin e de análise estatística. Conclui-se que os muros Institucionais são construídos vislumbrando a produção do conhecimento e as especificidades de cada área, se tornando um campo fechado com teorias alicerçadas em nichos, sem uma posição de base que sirva para outras ciências. Talvez esse seja o maior desafio das Universidades (observar os limites de suas disciplinas) para que de fato se observe a interdisciplinaridade na prática dentro da IES.

Palavras-chave: Interdisciplinaridade, Desafios contemporâneos, Práticas pedagógicas.

\section{Introdução}

O tema enfoca uma discussão sobre a dimensão acadêmica e as dificuldades e problemas enfrentados dentro das Instituições de Ensino Superior em relação à interdisciplinaridade como um caminho para o enfrentamento de desafios contemporâneos da educação brasileira e seus desdobramentos socioeducacionais e intelectuais, bem como se debruça numa leitura oriunda aos novos cenários e condicionantes nesta temática. As 
mudanças que vêm ocorrendo na vida social e produtiva humana colocam para as instituições universitárias o desafio de reorientar-se ao novo contexto educacional do Brasil.

No processo de constituição de sua identidade, as IES enfrentam o desafio de explicitar e tornar práticos os fundamentos epistemológicos que a sustentam, a partir de um rigoroso debruçar sobre a nova realidade emergente da crise da modernidade, em particular da crise do trabalho, de modo a bem definir quais são suas funções em atenção às demandas de uma sociedade que prima por humanização, por qualidade de vida, por justiça social e por sustentabilidade.

Do ponto de vista epistemológico, a nova institucionalidade se constrói a partir da compreensão que o conhecimento se produz a partir da prática e voltado para o enfrentamento das questões objetivas regidas pela atividade humana, ao mesmo tempo individual e coletiva, mas sempre histórica. Como consequência, dada a sua inserção regional, tem como princípio orientador a articulação dialética entre regionalização e globalidade, comunidade e universalidade, diferença e igualdade, na perspectiva de sua permanente relação com a prática social, como forma de superação dos modelos que a crise de paradigmas tornou anacrônicos.

De uma forma geral as IES ( Instituição de Ensino Superior) não se renovam em suas práticas pedagógicas, as técnicas impetradas nos currículos e nas salas de aula são quase sempre pouco inovadoras.

A construção da identidade, portanto, implica buscar novas formas de relação entre universidade, sociedade civil, governo e setor empresarial, em uma realidade dinâmica, instável, em constante construção, de modo a enfrentar os novos desafios da prática sem perder o distanciamento e a isenção inerente à sua própria natureza e que lhe conferem autonomia.

Desta forma, a Prática Interdisciplinar nas IES constitui uma ferramenta necessária para uma política institucional e legitima uma prática inovadora que estimula a sociedade a pensar, refletir, compreender e agir de forma consciente e preventiva frente aos desafios apresentados pela realidade.

Rescindir com essa tendência fragmentadora e deslocada é uma forma de contribuir para novos cenários de saberes, que quase sempre reproduzem um conhecimento 
parcelado que implica no cotidiano e nas relações de trabalho nas Instituições de Ensino Superior.

A interdisciplinaridade consiste na extrusão de uma ciência dura que propicia mudanças nas matrizes curriculares das escolas no ensino fundamental, básico e superior, como forma do aluno ser o mediador do seu conhecimento, buscando um domínio das suas investigações, revides de experiências e parcerias em diferentes ciências. Novas possibilidades pedagógicas impingem uma relação direta com o futuro espera-se que em 2020, haverá um novo perfil de Instituição e de aluno voltado às realidades da nova década que adentrarão. A tecnologia e o comportamento humano nesta dezena instará das IES novos paradigmas de gestão acadêmico-pedagógicas e administrativas.

Como observa Gusdorf (1967, p. 26):

a exigência interdisciplinar impõe a cada especialista que transcreva sua própria especialidade, tomando consciência de seus própria especialidade, tomando consciência de seus próprio limites para colher as contribuições das outras disciplinas.

Quiçá esse seja o maior repto (observar as fronteiras de suas disciplinas) para que de fato se ressalte a interdisciplinaridade na prática. A prática interdisciplinar perpassa pela mudança paradigmática na formação dos sujeitos, nos conteúdos disciplinares e na lógica de que uma disciplina por si só é a detentora do grande saber. Os currículos escolares quase sempre são engessados, arraigados de pré-requisitos, não permitindo ao alunado se aproximar dos desafios contemporâneos para exercer seu papel de cidadão dentro de uma sociedade tão excludente, como a nossa.

As Instituições de Ensino Superior tem que atentar as novas contextualizações vindouras das necessidades humanas e do avanço tecnológico, onde é impingido um modelo de gestão aberta, participativa e transversal de conhecimento e saberes transdisciplinares, com atores que atendam às múltiplas exigências dos novos cenários econômicos, regulatórios do Ministério da Educação-MEC e com uma capacidade de maximizar e experimentar novos enfrentamentos de um mercado absolutamente competitivo.

A IES terá que definir as políticas acadêmicas, sociais como forma de se fazer atuante no processo de educação e formação profissional e sensível aos problemas da comunidade. 
Desse modo, a designação pedagógica, somada com a qualificação social reafirma a missão na produção e na difusão do conhecimento das IES, assim como o compromisso com o avanço e as transformações tecnológicas e do conhecimento. Neste sentido, as estratégias das políticas das IES consistirão num cruzamento de campos que conectarão e confrontarão pontos de vista, implicando, portanto, na produção de sujeitos com mais senso crítico, excitabilidade estética e agudeza criativa.

Essa ação prática da ruptura do conhecimento técnico em prol de metodologias significativas, considerando às produções de sentido e de vida dos sujeitos. Expressando o aforismo humano em situações permanentes de interação e diálogo, em integração com o seu meio, em circulação de ponderação e de ambiguidade a respeito dos próprios dados e dos utensílios que produz ao mesmo tempo em que promove os valores éticos presentes na dependência recíproca, cooperação, tolerância, abertura diante do novo, no respeito à vida e suas manifestações.

Um espectro Interdisciplinar tem como indicador de sua atividade a práxis, no comedimento em que se baseia na experiência e se serve dela como material a ser retrabalhado teoricamente, tanto na relação professor-aluno quanto na relação de pesquisadores entre si. Ao operar com diferentes campos, o sujeito envolvido na rede Interdisciplinar — aluno ou professor — só acede a algum tipo de sistematização como efeito retroativo do ato conjunto de repensar a experiência, seja ela de cunho teórico, sensorial ou laboratorial. (FRANCO, 1997).

Segundo Franco (1997), o sujeito não reduzirá os episódios e o conhecimento. A práxis de sujeitos humanos, conjugando reflexão e ato rigorosos, que delimita/formata campos do saber, transformando-os em "uma ação realizada pelo homem, qualquer que seja ela, que o põe em condição de tratar o real pelo simbólico".

Os temas transversais são ferramentas necessárias para uma política institucional e legitima uma prática inovadora que estimula a sociedade a pensar, refletir, compreender e agir de forma consciente e preventiva frente aos desafios apresentados pela realidade (LONGHI, 1998).

Deste ponto de vista, uma IES Inovadora deve ter como projeto institucional não apenas a resposta a demandas locais e regionais, reais ou presumíveis, mas sua própria capacitação como agente fomentador de uma cultura na qual distintos grupos sociais se reconheçam, a despeito de seus interesses específicos, e reconheçam na pesquisa científica e 
tecnológica uma das chaves para seu desenvolvimento comum.

Abrolhar conhecimento e torná-lo acessível é o objetivo da universidade; A instrução é uma forma de efetivar este acesso. É através dele que as pessoas aprendem a modificar conhecimento e informação em comportamentos, ou seja, aprendem a utilizar a ciência nas diferentes circunstâncias da prática social.

A educação, portanto, é a forma, por nobreza, através da qual o conhecimento se legitima como mediação para o homem construir sua condição de existência, no contexto histórico-social em que ela se revela. Assim abarcado, é prática simultaneamente técnica e política, atravessada por uma intencionalidade teórica, fecundada pela significação simbólica, mediando a integração dos sujeitos educandos nesse tríplice universo das mediações existenciais: no universo do trabalho, da produção material, das relações econômicas; no universo das mediações institucionais da vida social, lugar das relações políticas, esfera do poder; no universo da cultura simbólica, lugar da experiência da identidade subjetiva, esfera das relações intencionais. A educação só se legitima intencionalizando a prática histórica dos homens ${ }^{1}$.

No ensino superior de graduação, o acesso ao conhecimento possui características mais complexas e socialmente mais abrangentes, contribuindo para o processo de humanização através da capacitação dos alunos para trabalhar com o conhecimento e com a tecnologia mais avançados disponíveis; derivar, da pesquisa e do conhecimento mais recentes, novas formas de conduta pessoal e social; integrar dados e informações de diferentes áreas, formas e tipos de conhecimento; analisar e avaliar criticamente a sociedade e sua própria participação nela, e trabalhar profissionalmente em níveis de atuação mais preponderantemente de melhoramento ou de manutenção das condições de vida com qualidade ${ }^{2}$.

A prática social, portanto, constitui-se em ponto de arranque e ponto de advento para as práticas acadêmicas. Essas mudanças, que conformam um novo regime de acumulação - a unificação flexível, que se materializa na relação entre concentração crescente do capital e geração igualmente crescente da exclusão através da mundialização do capital, da reestruturação produtiva e das novas de regulação através do Estado - têm trazido profundas

\footnotetext{
1 SEVERINO, A .J. Consolidação dos cursos de pós-graduação em educação: condições epistemológicas, políticas e institucionais. In: SEVERINO, A J. Conhecimento, pesquisa e educação. Campinas: Papirus, 2001, p. 53.

2 BOTOMÉ, S. Pesquisa alienada e ensino alienante: o equívoco da extensão universitária. Petrópolis: Vozes, 1996, p. 125.
} 
consequências para a educação em geral, atingindo de forma muito intensa o ensino superior.

Sob a preeminência do modo taylorista/fordista de organização e gestão do trabalho, com a sua bem delimitada divisão de tarefas entre as funções intelectuais e as instrumentais, a par de uma concepção positivista de ciência que fragmenta os diversos campos do conhecimento em áreas rigidamente definidas, a função do Ensino Superior consistia na formação de quadros especializados para atender às demandas de uma produção cada vez mais diversificada, a exigir ramificações cada vez mais recortadas no campo da qualificação profissional para todos os setores da economia.(LONGHI,1998).

As profissões de nível superior, com foco no mercado, eram rigorosamente estabelecidas, para o que concorriam as corporações, através da regulamentação das atividades profissionais.

Em uma economia pouco dinâmica, do ponto de vista das mudanças científicotecnológicas e próxima do pleno emprego, a norma era a estabilidade, a partir da especialização. Assim, o curso superior era, ao mesmo tempo, formação inicial e final, não se colocando a educação continuada como necessidade; a partir de um currículo que se iniciava com uma base de formação geral, seguida de formação especializada para um campo profissional e, às vezes, de estágio ao final do curso, buscava-se articular os conhecimentos teóricos aos necessários à prática do trabalho. A concepção de currículo mínimo refletia o empenho em conferir organicidade entre a formação e o exercício profissional porquanto estabelecia os conhecimentos que eram necessários, em âmbito nacional, à formação para cada trabalho especializado. Uma vez formado, o egresso do Ensino Superior, de modo geral, conseguia um trabalho na sua área de formação e, caso desempenhasse com competência suas atribuições, gozava de estabilidade, sem que dele se exigisse grande esforço de atualização além dos necessários para acompanhar mudanças que ocorriam de forma gradual, em face da baixa dinamicidade do desenvolvimento científico-tecnológico, que eram absorvidas quase que "naturalmente”.(LONGHI,1998).

A dinamicidade que o desenvolvimento científico-tecnológico imprime aos processos produtivos e sociais muda radicalmente esta modalidade de formação, definida a partir da rigidez taylorista/fordista. As mudanças muito rápidas passam a exigir atitudes diferentes com relação ao conhecimento.

Quanto mais se simplificam as tarefas, mais se exige conhecimento do profissional e não mais relativo ao saber-fazer, cada vez menos necessário. Ao contrário, a 
crescente complexificação dos instrumentos de produção, informação e controle, nos quais a base eletromecânica é substituída pela base microeletrônica, passam a exigir o desenvolvimento de competências cognitivas superiores e de relacionamento, tais como análise, síntese, estabelecimento de relações, criação de soluções inovadoras, rapidez de resposta, comunicação clara e precisa, interpretação e uso de diferentes formas de linguagem, capacidade para trabalhar em grupo, gerenciar processos para atingir metas, trabalhar com prioridades, avaliar, lidar com as diferenças, enfrentar os desafios das mudanças permanentes, resistir a pressões, desenvolver o raciocínio lógico-formal aliado à intuição criadora, buscar aprender permanentemente e assim por diante.

A formação profissional passa a exigir capacidade para lidar com a incerteza, com a novidade e para tomar decisões rápidas em situações inesperadas.

$\mathrm{O}$ arquivamento de métodos cogentes a um bom desempenho em processos fecundos austeros, típicos do regime anterior de ajuntamento com base no taylorismo/fordismo, decorre a ser suprida pela capacidade de usar a noção científica de todas as áreas para resolver problemas novos de modo original, o que implica em domínio não só de conteúdos, mas dos logradouros metodológicos e das formas de trabalho intelectual multidisciplinar, o que exige educação inicial e continuada severa, em níveis crescentes de complexidade. Ou seja, de maior aspereza acadêmica, agregado à competência investigativa, de caráter a integrar ciência e mudança social através da práxis.

A esta competência científico-tecnológica, digo a demanda por competência ética, na dimensão do pacto político com a qualidade da vida social e produtiva. Ao mesmo tempo, exigem-se novos desempenhos, em passagem das novas formas de organização e gestão do trabalho, nas quais as práticas individuais são substituídas por procedimentos cada vez mais coletivos, nos quais se compartilham a produção de sentidos e de vida do sujeito, levando em consideração as singularidades e pluralidades destes. Ao avesso de um laborioso que simplesmente aceita a autoridade socialmente reconhecida, externa a ele, demanda-se um trabalhador com autonomia ética para discernir, ponho-se uma nova juntura entre constrangimentos externos e espaços individuais de decisão.

A posse destas características é que vai definir o ingresso e a permanência no mundo do trabalho, o que cada vez mais depende de diferenciação e sofisticação de trajetórias, a partir de uma base comum de conhecimentos. A uniformidade decorrente da certificação escolar, complementada pela formação profissional, adquirida em cursos técnicos 
ou superiores, que assegurou às antigas gerações o ingresso e a permanência no emprego, já não é mais suficiente.

Em decorrência, a proposta para o Ensino Superior, a partir das novas políticas e diretrizes curriculares nacionais, passa por significativas transformações conceituais; da formação especializada passa-se à formação do generalista; dos currículos mínimos passa-se às diretrizes curriculares amplas, que serão adequadas a cada curso, segundo as peculiaridades locais e dos alunos; de trajetórias unificadas, passa-se à diversificação dos percursos.

Estes princípios configuram outras formas de organização dos percursos curriculares, em que a uma base de formação geral de natureza interdisciplinar suceda a possibilidade de escolhas de áreas específicas, dando-se a formação no próprio curso ou através da educação continuada e/ou da pós-graduação; ainda, em face da nova exigência de diversificação da formação. Contrariamente à padronização taylorista/fordista, a flexibilização curricular permite que o aluno escolha, no seu percurso formativo, disciplinas e atividades complementares que confiram uma certa originalidade à sua formação, de modo não apenas a atender às suas preferências, mas, principalmente, ampliar a sua empregabilidade.

É nesta linha que as ações do MEC e do Conselho Nacional de Educação, a partir das propostas das comissões de especialistas, discutiram e aprovaram as Diretrizes Curriculares para os cursos de graduação.

Nesta nova concepção, o ensino superior toma a formação geral como estratégia para enfrentar a dinamicidade das mudanças no mundo do trabalho; ao mesmo tempo, adota a flexibilização dos percursos como estratégia de empregabilidade. Com a flexibilização, as Instituições de Ensino Superior livram-se do engessamento decorrente dos currículos mínimos, de modo a assegurar autonomia na composição da carga horária a ser cumprida para a integralização de cada curso. De modo geral, há uma tendência ao enxugamento dos cursos, devendo-se evitar o seu prolongamento desnecessário, uma vez que a formação profissional não se encerra, apenas se inicia no ensino superior; sua complementação vai se dando ao longo da vida social e produtiva.

Em que pese boa parte desta argumentação resultar da crítica a propostas de cunho teoricista com discutível valor formativo, uma análise mais aprofundada da nova concepção de ensino superior aponta contradições que podem se transformar em riscos. A defesa de uma formação flexível, que realmente supere o formalismo teoricista das propostas atuais, a considerar as novas demandas do mundo do trabalho, não pode conduzir à 
precarização dos percursos formativos, através da desvalorização da teoria e da redução excessiva da duração dos cursos de graduação.

Há que considerar que a progressiva perda de conteúdo do trabalho, que vai se tornando cada vez mais abstrato pela crescente incorporação de ciência e tecnologia ao processo produtivo para atender aos objetivos da acumulação, faz com que as habilidades cognitivas, até então restritas a um número reduzido de profissionais, passe a ser requerida para o conjunto dos trabalhadores. Embora este processo não atinja da mesma forma o conjunto das atividades produtivas, não podendo a nova demanda ser generalizada, aos novos paradigmas corresponde uma nova cultura, marcada pela presença de novas tecnologias que permanentemente se transformam, e ao fazê-lo, também transformam todas as dimensões da vida social e produtiva, embora com impactos diferenciados, particularmente em um país como o Brasil, no qual as desigualdades são muito acentuadas.

Assim, do homem comum de massa passou-se a exigir um aporte mais ampliado de conhecimentos e habilidades cognitivas superiores, para que possa participar da vida social e produtiva. Embora os postos de trabalho diminuam de forma acentuada, como consequência da acumulação flexível, as mudanças ocorridas no mundo do trabalho passam a exigir realmente uma nova relação com o conhecimento para que se possa viver em sociedade, redefinindo-se a concepção de ensino superior quanto às suas finalidades formativas.( FRANCO,1997).

Exemplos desta afirmação podem ser as novas demandas relativas à preservação ambiental, em face do caráter destruidor do modo de produção de mercadorias; ou a necessidade de maiores aportes de conhecimento sobre saúde e segurança no trabalho, para prevenir patologias de outra natureza e não menos perversas; ou a necessidade de conhecer as normas que regem a produção, a circulação e o financiamento das mercadorias, do ponto de vista da internacionalização e do consumo individual.

Evidencia-se a necessidade de apropriação de conhecimentos científicos, tecnológicos e sociohistóricos, com particular destaque para as formas de comunicação e de organização e gestão dos processos sociais e produtivos, como condição de inclusão. Mas não só, uma vez que a dinamicidade dos processos de produção do conhecimento, que constantemente obsoletizam o já conhecido, trazendo novas demandas, exigem também a capacidade de aprender os caminhos através dos quais os conhecimentos são produzidos, ou seja, o método. 
A competência, diferentemente do que ocorria no taylorismo/fordismo, passa a ser concebida como "a capacidade de agir, em situações previstas e não previstas, com rapidez e eficiência, articulando conhecimentos tácitos e científicos a experiências de vida e laborais...vinculada à ideia de solucionar problemas, articulando conhecimentos de forma transdisciplinar a comportamentos e habilidades psicofísicas e transferindo-os para novas situações; supõe, portanto, a capacidade de atuar mobilizando conhecimentos"”.

Abre-se, portanto, um novo espaço para a discussão de uma pedagogia voltada para as demandas da vida social e produtiva que, entre outras dimensões, deverá contemplar os conteúdos e suas formas metodológicas a partir de outra lógic que não a do ensino tradicional.

Além da densidade teórica necessária ao desenvolvimento da capacidade de usar a ciência de forma criativa e crítica, para enfrentar os desafios de uma vida social e produtiva extremamente dinâmica, um ensino superior realmente transformador privilegiará a qualidade à quantidade. Esta qualidade só se estabelecerá a partir do momento em que o aluno passe a ter o direito de elaborar suas próprias sínteses em uma escola adequadamente equipada, substituindo-se a concepção hoje dominante de trabalho pedagógico, na qual o professor, ator central do processo, autoritariamente transmite a sua síntese particular, não permitindo ao aluno construir significados e desenvolver suas competências cognitivas complexas e éticas em situações de aprendizagem planejadas para esta finalidade. Isto leva tempo e exige atendimento que articule momentos individualizados para momentos de elaboração coletiva.

A concepção de ensino adotada, que decorre da já explicitada concepção de produção do conhecimento, aponta, ainda, para o fato de que a sequência metodológica “preleção, fixação, avaliação" toma por objeto o conhecimento sistematizado no seu mais alto grau de abstração e generalidade, o que vale dizer, como resultado final de um processo de construção que articulou inúmeros e diversificados movimentos do pensamento coletivo e deu-se em um determinado tempo e espaço para satisfazer uma determinada necessidade da existência humana. Descolado deste movimento e desta prática e, portanto, de sua historicidade, este conhecimento dificilmente terá significado para um estudante que recebeu a tarefa de incorporá-lo a partir de sua expressão mais formalizada e estática. Daí as críticas feitas ao ensino sobre a incapacidade dos alunos relacionarem os conteúdos das disciplinas

\footnotetext{
${ }^{3}$ KUENZER, A . Conhecimentos e competências no trabalho e na escola. Boletim Técnico do Senac, Rio de Janeiro, v. 28, n. 2 , mai./ago. 2002. p. 8.
} 
com as relações sociais e produtivas que constituem a sua existência individual e coletiva. Essas críticas reforçam a necessidade da historicização e do protagonismo do aluno no processo de conhecer.

Da mesma forma, a dinamicidade da produção científico-tecnológica contemporânea aponta para um princípio educativo que, sem chegar ao exagero de tomar os conteúdos como pretexto, como se fosse possível um novo formalismo (apreender os processos de construção do conhecimento, os novos comportamentos, independentemente do conteúdo a ser conhecido), privilegie a relação entre o que precisa ser conhecido e o caminho que precisa ser trilhado para conhecer, ou seja, entre conteúdo e método, na perspectiva da construção da autonomia intelectual e ética. Estabelece-se, assim, uma forte articulação entre ensino e pesquisa, a partir das concepções elencadas, que orientarão as práticas pedagógicas na Instituição.

Este é um fato importante a destacar, em face da sua positividade: o deslocamento da memorização, até então considerada a habilidade mais importante a ser desenvolvida através da repetição, para as habilidades cognitivas complexas, que passa a mover o eixo do currículo dos conteúdos tomados em si para a adequada relação entre conteúdo e método. Isto significa que as mudanças trazidas pela microeletrônica estimulam a superação do conceito de conteúdo enquanto produto acabado do pensamento humano, que deve ser apropriado, para uma concepção que privilegia o conteúdo incorporado a processos, o que exige uma adequada proposta metodológica que tome como ponto de partida o modo como o homem produz conhecimento a partir da prática social, ou seja, a epistemologia.

Outra dimensão importante da concepção adotada de ensino de graduação é que os conteúdos que tradicionalmente compunham as propostas curriculares das ciências humanas e sociais passam a integrar a formação dos profissionais das áreas científicas e tecnológicas. São as mudanças no mundo do trabalho que, ao derrubar as barreiras entre as áreas do conhecimento a partir da nova realidade do trabalho, derrubam esta divisão que, por muito tempo, foi cara ao ensino superior, através da divisão entre ciência básica e aplicada, entre humanidades e tecnologia. Ao mesmo tempo, derrubam-se as barreiras existentes entre prática acadêmica e prática social, vinculando o ensino à extensão no processo de formação humana.

A quebra destas barreiras implica em uma nova concepção de universidade, que está sendo estimulada a derrubar os limites dos seus espaços fechados, para construir 
propostas curriculares que integrem os cursos à sociedade; no limite. Evidencia-se o caráter arcaico da estrutura de grande parte das IES, cuja fragmentação foi reforçada pela legislação da ditadura militar e que agora terá que ser superada por força da imposição das mudanças ocorridas no mundo do trabalho (LONGHI,1998).

A partir das novas diretrizes curriculares, as Instituições de Ensino Superior serão forçadas a superar a fragmentação de suas estruturas e currículos taylorizados, em busca de formas mais leves, enxutas e ágeis de organização e gestão, e de currículos de natureza Interdisciplinar. Nesta mesma linha, destaca-se o impulso à superação do conteudismo por uma adequada relação entre conteúdo e método, que também não recaia em simplificação comportamentalista, forma de racionalização pedagógica que expressa o movimento de racionalização e intelectualização por que passam as sociedades contemporâneas, como expressão do cálculo econômico, da razão científica e técnica e da planificação tecnicista.

\section{Objetivo Da Pesquisa}

Analisar as práticas estabelecidas nos cursos de graduação no ensino superior num Centro de Ciências da Saúde na concepção interdisciplinar.

\section{Metodologia}

Como um estudo piloto, "O Desafio da Multidisciplinaridade: Caminhos Brasileiros da Graduação e Pós-Graduação e Sinalizações Internacionais", supervisionado pela Professora Maria Estela Dal Pai Franco, do Grupo GEU da Universidade Federal do Rio Grande do Sul (UFRGS). Ao tomar consciência da necessidade de produção do conhecimento, novos cenários e determinantes da educação do nosso País, este pesquisador sente chamado a participar desse debate e contribuir para enfrentar esses desafios que são colocados para a sociedade na atualidade.

Em relação aos eixos metodológicos, o estudo é de natureza qualitativa e quantitativa. A pesquisa foi realizada através de um estudo de caso numa Universidade na região Sul no Brasil nos cursos de graduação do Centro de Ciências da Saúde - CCS (Terapia Ocupacional / Fonoaudiologia / Fisioterapia / Farmácia / Odontologia), através do qual 
intenciona-se em produzir teorias que possam corroborar para a construção de novas ferramentas para os diversos autores da Educação, Instituições de Ensino Superior que, por ventura, se interessem na temática apresentada.

Para coleta dos dados da pesquisa em relação à Graduação, foram entrevistados 30 (trinta) docentes da graduação na IES nos 05 (cincos) cursos do Centro de Ciências da Saúde já supramencionados.

\section{Análise dos resultados}

A pesquisa vislumbrou compreender melhor o objeto de interesse do pesquisador, a partir das análises das falas dos docentes, partindo de 2 (duas) perguntas delineadoras: quais as práticas estabelecidas nos cursos dentro de uma concepção interdisciplinar? Quando ocorrem e quando não ocorrem. Há necessidade de produzir conhecimento a partir de uma prática interdisciplinar?

Sobre as práticas estabelecidas nos cursos dentro de uma concepção interdisciplinar e quando ocorrem, $75 \%$ dos professores afirmaram que estas acontecem de forma transversal nos cursos; $67 \%$ relataram que ocorrem nos eixos comuns das disciplinas durante as elaborações dos planos de ensino; $53 \%$ asseveraram que incidem nas conversas formais e informais sobre os conteúdos a serem trabalhados; 30\% durante as práticas ocorridas dentro do Hospital Universitário e 21\% alegaram que acontecem no exercício laborial em sala de aula.

\footnotetext{
"A prática interdisciplinar ocorre na relação direta do conhecimento. O aluno necessita dos conteúdos da anatomia para trabalhar com as especificidades da área de Farmácia."

"O modo transversal dos conteúdos é a forma como compreendo que trabalhamos com a prática interdisciplinar. Nenhuma ciência se sustenta sem o diálogo com outras disciplinas."
}

As falas dos docentes remontam aos princípios epistemológicos de Japiassu (1976), que afiança que o resultado da relação interdisciplinar seria a troca intensa de instrumentos e técnicas metodológicas, a fim de que, no final do processo, todos os profissionais saíssem extremamente enriquecidos. 
$\mathrm{O}$ autor defende, ainda, que a interdisciplinaridade, nesse caso, corresponde à necessidade de superar a visão fragmentadora da produção do conhecimento, bem como articular e produzir coerência entre os múltiplos fragmentos que estão colocados no acervo do conhecimento da humanidade.

"Estamos conversando o tempo inteiro, trocando ideias, sejam no ensino, na pesquisa e na extensão. Isto é ou não é uma prática interdisciplinar?"

"No hospital trabalhamos nos holdings os casos de cada paciente e as contribuições da diferentes áreas do conhecimento."

Concorda-se com Japiassu (1976) quando este afirma que a interdisciplinaridade poderá: ampliar a formação geral de pesquisadores das especialidades envolvidas, levando-os a rever seu papel social e as posturas críticas diante das informações percebidas, no excerto verificado acima, o conteúdo da fala do docente suscita que há uma prática interdisciplinar, assumindo que há conversas no tripé ensino, pesquisa e extensão na IES, bem como nos estudos de casos dos usuários no hospital universitário.

A seguir, no estudo, analisa-se a segunda pergunta delineadora, quando não ocorrem as práticas interdisciplinares nas relações cotidianas do trabalho: $25 \%$ dos professores avalizaram que na graduação não há prática interdisciplinar; $22 \%$ afirmaram que a UFSM não estimula essa prática; $13 \%$ afirmaram que desconhecem o que seria uma prática interdisciplinar, $40 \%$ se omitiram em responder, opta-se analisar um excerto que particularmente nos chamou atenção.

"Essa história de interdisciplinaridade é das ciências humanas. Trabalhamos com seres humanos de forma pragmática. Não temos tempo para filosofar."

Em relação às dificuldades de se conseguir uma ação interdisciplinar na prática desses professores da área da saúde, os profissionais são unânimes em afirmar que a ação interdisciplinar é difícil devido às questões pessoais e institucionais.

"Eu acho que menos da metade sabe o que é isso: ação interdisciplinar. Agora, imagine trabalhar dessa forma. As pessoas aqui estão ilhadas nos seus problemas pessoais, nas suas vidas, na ganância de poder, de dinheiro, de ter e possuir mais..." 
Refletindo sobre estes dados, percebe-se que, na prática profissional, a interdisciplinaridade não vem conseguindo uma efetivação no cotidiano, confirmando a preocupação que Japiassu expressou nesse breve comentário:

O conhecimento interdisciplinar, até bem pouco tempo condenado por ostracismo pelos preconceitos positivistas, fundados numa epistemologia da dissociação do saber, começa a ganhar direitos de cidadania, a ponto de correr o risco em moda (FAZENDA,1998, p.30).

Os professores revelaram dificuldades e entraves humanos e materiais para a implantação da interdisciplinaridade na instituição.

Definir uma prática interdisciplinar, atualmente, não significa apenas a reunião ou edição das várias disciplinas, das especialidades, nem tampouco cada especialista se justapor por interesse que não lhe é comum. Segundo Fazenda (1998), a interdisciplinaridade deixa de ser hoje um simples produto de ocasião para tornar-se a própria condição do progresso das pesquisas nas ciências humanas.

Na segunda pergunta norteadora: há necessidade de produzir conhecimento a partir de uma prática interdisciplinar? $77 \%$ dos professores asseveraram que sim e $21 \%$ afirmaram que não.

As falas dos docentes assoalharam que os professores no seu cotidiano dentro da Universidade buscam uma prática interdisciplinar, embora ainda haja um desconhecimento eminente sobre esse exercício já que essa prática é pautada no jogo dialético entre o equilíbrio e o desafio, que pode ser percebido no relato da prática profissional. Operar de forma interdisciplinar consiste em construir coletivamente o saber, buscando o novo, o risco, a descoberta, o diálogo, a troca, o conhecer juntos, deixando que cada um assuma sua própria prática dentro dos próprios limites.

\footnotetext{
"Há necessidade de romper com a tendência fragmentadora e desarticuladora do conhecimento."

"É uma forma de institucionalizar a produção do conhecimento, pluralidade de saberes e trocas de aprendizagem. Cada ciência produz seu conhecimento próprio".
}

Segundo Petraglia (1993), a interdisciplinaridade é uma atitude, uma maneira de perceber, de conduta e concepção de vida. Sua importância e necessidade partem da crença e 
dos valores de cada um. Dessa forma, não pode ser imposta por um sistema. A interdisciplinaridade não se faz por decreto, mas por vontade de aprender e desenvolver.

Por fim, não se faz interdisciplinaridade de maneira consequente e séria sem uma filosofia e uma antropologia discutidas e admitidas.

Salienta-se que a interdisciplinaridade propõe que os dialogantes não sejam ciências abstratas, mas pessoas que procedem por decisões, opções e valores, não cabe uma atitude de dominação nem entre ciências nem entre pessoas. A ciência deve, por fim, cultivar uma virtude humanizadora. Em boa parte, tais inquietações e atitudes têm inspirado o surgimento da interdisciplinaridade nas ações profissionais.

\section{Considerações Finais}

No Centro de Ciências da Saúde (CCS) da Intituição investigada, os cursos primam por práticas voltadas à doença, por vezes consideradas reducionista. A prática interdisciplinar, enquanto processo de integração recíproca, é fragmentada na vivência diária dos professores no Centro de Ciências da Saúde.

A inópia de romper com a tendência fragmentadora e desarticulada do processo do conhecimento desculpa-se pela compreensão da importância da interação e transformação recíprocas entre as diferentes áreas do saber. Essa compreensão crítica colabora para a superação da divisão do pensamento e do conhecimento, que vem colocando a pesquisa e o ensino como processo reprodutor de um saber parcelado. Essa ação repercute na pósgraduação, na qual se constata uma incipiência nas propostas interdisciplinares.

Os muros departamentais são presentes nos cotidianos da IES. Há necessidade se construir novos paradigmas pedagógicos para que esses muros sejam rompidos. Deve haver uma nova articulação de novos modelos curriculares e na comunicação do processo de perceber as várias disciplinas, nas determinações do domínio das investigações, na constituição das linguagens partilhadas, nas pluralidades dos saberes, nas possibilidades de trocas de experiências e nos modos de realização da parceria

\section{REFERÊNCIAS}

FRANCO, M. E. D. P. (org.). Universidade, pesquisa e inovação: o Rio Grande do Sul em perspectiva. Passo Fundo: Ediupf; Porto Alegre: Edipucrs, 1997. 
FAZENDA, I. C. A.. Interdisciplinaridade: história, teoria e pesquisa. 3. ed. Campinas: Papirus, 1998.

GUSDORF, G. Des sciences de l'homme sont des sciences humaines.

Strasbourg: Editrice de L'Université de Strasbourg, 1967.

JAPIASSU, H. Interdisciplinaridade e patologia do saber. Rio de Janeiro:

Imago, 1976.

LONGHI, S. M. A face comunitária da universidade. Tese (Doutorado em Educação).

Universidade Federal do Rio Grande do Sul, Porto Alegre, 1998.

PETRAGLIA, I. C. Interdisciplinaridade: o cultivo do professor. São Paulo: Pioneira; USF, 1993.

Data de recebimento: 09/01/14

Data de aceite: $28 / 07 / 16$

Sobre o autor:

Francisco Nilton Gomes de Oliveira é Docente do Departamento de Terapia Ocupacional da UFSM. Doutor em Linguística e Pós Doutor em Educação. Endereço eletrônico:

nitlonoliveira@superig.com.br 